\title{
Cortical Activation Associated with Muscle Synergies of the Human Male Pelvic Floor
}

\author{
Skulpan Asavasopon, ${ }^{1 \star}$ () Manku Rana, ${ }^{2 \star}$ Daniel J. Kirages, ${ }^{2}$ Moheb S. Yani, ${ }^{2}$ Beth E. Fisher, ${ }^{2,5}$ Darryl H. Hwang, ${ }^{3}$ \\ Everett B. Lohman, ${ }^{1}{ }^{\circledR}$ Lee S. Berk, ${ }^{1,4}$ and ${ }^{\circledR}$ Jason J. Kutch ${ }^{2}$ \\ ${ }^{1}$ Physical Therapy Department, Loma Linda University, Loma Linda, California 92350, ${ }^{2}$ Division of Biokinesiology and Physical Therapy and ${ }^{3}$ Department \\ of Radiology, University of Southern California, Los Angeles, California 90033, ${ }^{4}$ Department of Pathology and Human Anatomy, Loma Linda University, \\ Loma Linda, California 92350, and ${ }^{5}$ Department of Neurology, University of Southern California, Los Angeles, California 90033
}

\begin{abstract}
Human pelvic floor muscles have been shown to operate synergistically with a wide variety of muscles, which has been suggested to be an important contributor to continence and pelvic stability during functional tasks. However, the neural mechanism of pelvic floor muscle synergies remains unknown. Here, we test the hypothesis that activation in motor cortical regions associated with pelvic floor activation are part of the neural substrate for such synergies. We first use electromyographic recordings to extend previous findings and demonstrate that pelvic floor muscles activate synergistically during voluntary activation of gluteal muscles, but not during voluntary activation of finger muscles. We then show, using functional magnetic resonance imaging (fMRI), that a region of the medial wall of the precentral gyrus consistently activates during both voluntary pelvic floor muscle activation and voluntary gluteal activation, but not during voluntary finger activation. We finally confirm, using transcranial magnetic stimulation, that the fMRI-identified medial wall region is likely to generate pelvic floor muscle activation. Thus, muscle synergies of the human male pelvic floor appear to involve activation of motor cortical areas associated with pelvic floor control.
\end{abstract}

Key words: EMG; fMRI; motor cortex; pelvic floor; supplementary motor area; TMS

\section{Introduction}

There is a large body of literature demonstrating that muscles of the human pelvic floor-that is, muscles of the perineum and rectum that contribute to the control of urination, defecation, and sexual activity - are activated synergistically with nonpelvic floor muscles during functional tasks. For example, pelvic floor muscles (PFM) are active during voluntary activation of abdominal muscles (Sapsford and Hodges, 2001; Madill and McLean, 2008), gluteal muscles (Floyd and Walls, 1953; Bø and Stien, 1994; Peschers et al., 2001), hip adductors (Bø and Stien, 1994), and even during voluntary shoulder flexion or extension (Hodges et al., 2007; Sjödahl et al., 2009). PFM synergies have been suggested to be an important mechanism to promote continence by resisting increased intra-abdominal pressure generated by functional tasks (Junginger et al., 2010).

Received May 20, 2014; revised Aug. 4, 2014; accepted Sept. 4, 2014.

Author contributions: S.A., M.R., M.S.Y., and J.J.K. designed research;S.A., M.R., M.S.Y., and D.H.H. performed research;S.A., M.R., M.S.Y., and J.J.K. analyzed data;S.A., M.R., D.J.K., B.E.F., E.B.L., L.S.B., and J.J.K. wrote the paper.

The contents of this research paper were developed in part under support from the USC Division of Biokinesiology and Physical Therapy, Loma Linda University Physical Therapy Department, and National Center for Medical Rehabilitation Research of the National Institutes of Health under award number T32 HD064578. Its publications are solely the responsibility of the authors and do not necessarily represent the official views of the National Institutes of Health. We thank Dr. Ya-Yun Lee for assistance with protocol development, and all of the research participants for their time.

*S.A. and M.R. contributed equally to this work.

The authors declare no competing financial interests.

Correspondence should be addressed to Jason J. Kutch, University of Southern California, 1540 E. Alcazar Street, CHP 155, Los Angeles, CA 90033. E-mail: kutch@usc.edu.

DOI:10.1523/JNEUROSCI.2073-14.2014

Copyright $\odot 2014$ the authors $\quad 0270-6474 / 14 / 3413811-08 \$ 15.00 / 0$
Despite the potential relevance of PFM synergies to prevalent clinical conditions, including incontinence (Bø and Stien, 1994; Sapsford and Hodges, 2001; Parekh et al., 2003; Ashton-Miller and DeLancey, 2007) and chronic pelvic pain (DoggweilerWiygul and Wiygul, 2002; Doggweiler-Wiygul, 2004), the neural centers responsible for these synergies are poorly understood. While many muscle synergies are likely shaped by subcortical connections (Mussa-Ivaldi et al., 1994; Saltiel et al., 2001; Cheung et al., 2009), there is evidence of cortical involvement in structuring muscle synergies (Rathelot and Strick, 2006; Drew et al., 2008; Waters-Metenier et al., 2014). Synergistic pelvic floor activation has been shown to occur in advance of activation in the primary muscles used to complete a task (Sapsford and Hodges, 2001; Hodges et al., 2007), suggesting that PFM activation may be part of a feedforward synergy. Since extensive research has demonstrated the cortical underpinnings of feedforward synergies (Aruin, 2002; Jacobs et al., 2009), we hypothesized that PFM synergies may be associated with activity in specific motor cortical areas that generate PFM activation.

A long line of evidence, dating back to at least Leyton and Sherrington (1917), demonstrates that pelvic floor musculature is represented in the medial wall of the precentral gyrus (Leyton and Sherrington, 1917; Turnbull et al., 1999; Schrum et al., 2011). We hypothesized that, if motor cortex is associated with pelvic muscle synergies, there would be a medial wall region that was active during voluntary pelvic floor activation and voluntary activation of synergists, and that moreover, stimulation of this region would generate pelvic floor activation. Using a combination 
of electromyographic (EMG) recording, functional magnetic resonance imaging (fMRI), and transcranial magnetic stimulation (TMS), we present data below in support of this hypothesis.

\section{Materials and Methods}

Participant population. We recruited 16 healthy males with a mean age $( \pm S D)$ of $32.63 \pm 5.89$ years (range: $24-43$ years). Since possible sex differences in the control of PFM have not been fully characterized, we limited our study to a single sex as in previous studies (Seseke et al., 2006; Schrum et al., 2011). Participants were practicing physical therapists or physical therapy students with general knowledge of pelvic floor anatomy and function. The studies we describe here were performed at the University of Southern California and approved by the University of Southern California Institutional Review Board. All participants provided informed consent.

EMG acquisition and analysis. In 10 participants, we measured muscle activation using EMG to define the characteristics of PFM synergies before performing the same tasks using fMRI to define the neural substrate. We used EMG to verify the previously reported muscle synergy between the PFM and gluteus maximus muscle (GMM) and to establish finger muscle activation as an appropriate control muscle group that does not have synergistic coupling with the PFM muscles (Floyd and Walls, 1953; Bø and Stien, 1994; Peschers et al., 2001). With the participant resting in a supine position inside a mock magnetic resonance imaging (MRI) scanner, we recorded surface EMG data from the right GMM, the PFM, and the right first dorsal interosseous muscle (FDI). We recorded EMG signals from the GMM and FDI with miniature electrode/preamplifiers (DELSYS) with two silver recording surfaces, $5 \mathrm{~mm}$ long and $10 \mathrm{~mm}$ apart. We recorded an EMG signal from the PFM using a medical-grade rectal EMG sensor (Pathway Rectal EMG Sensor, The Prometheus Group), which provided a bipolar recording from two bar electrodes, 12 $\mathrm{mm}$ apart, with dimensions $30 \mathrm{~mm}$ by $7 \mathrm{~mm}$, mounted longitudinally along a cylindrical plug-type applicator.

The rectal EMG sensor likely recorded an aggregate signal from the PFM muscles that included the anal sphincter and levator ani, with possible small contributions from more distant muscles such as bulbospongiosus. The EMG preamplifier filters had a bandwidth of $20-450 \mathrm{~Hz}$, with gains of 1000 for GMM and FDI, 10,000 for PFM, and a sampling rate of $2000 \mathrm{~Hz}$. PFM muscle activity has been previously measured using a rectal sensor, and is distinct from GMM surface EMG (Bø and Stien, 1994). Utilizing visual feedback training, it has been previously demonstrated that muscle activity can be recorded from a gluteal surface electrode while maintaining baseline levels of rectal EMG (Hodges et al., 2007), suggesting limited EMG cross talk between these recording sites. We performed an EMG cross-correlation analysis to estimate cross talk between EMG signals from the PFM and GMM during steady periods of GMM contraction using previously established methods (Winter et al., 1994). Cross-correlation of $<6 \%$ is expected for coactivated antagonist muscles and is considered negligible (Aagaard et al., 2000).

Before the experimental session, we asked participants to empty their bladder. Participants performed separate trials, each of which involved voluntary activation of a different primary muscle group. In PFM trials, we instructed participants to contract their PFM as if to stop the flow of urine. In GMM trials, we instructed participants to isometrically contract their GMM. In FDI trials, we instructed participants to contract their FDI muscle to generate index finger abduction. For all trial types, we first acquired EMG data corresponding to maximal voluntary contraction (MVC). During subsequent trials, participants activated the appropriate muscle group according to an audio tone that ramped up and down in frequency to guide the participant through a smooth activation over a period of $2 \mathrm{~s}$. Each trial consisted of two blocks of 10 activations. Previous studies of brain activity during PFM activation have not used EMG in the scanner (Seseke et al., 2006; Kuhtz-Buschbeck et al., 2007; Schrum et al., 2011). Since we planned to repeat voluntary activation trials in the fMRI scanner without EMG, we instructed participants to produce moderate muscle activation ( $\sim 20 \%$ effort) to avoid fatigue during the EMG portion of the study that was performed in the mock MRI. This activation was quantified and expressed as percentage MVC (expressed as \%MVC).
We analyzed EMG data to first estimate the activation onsets of the primary muscle group of each trial, and then to determine whether significant time-locked activity occurred in EMG signals from the other recorded muscles. To perform this analysis, EMG signals from all recorded muscles were first high-pass filtered at $100 \mathrm{~Hz}$ (fourth-order zerolag Butterworth filter), rectified, low-pass filtered at $30 \mathrm{~Hz}$ (Hodges et al., 2007), and then normalized to identically processed EMG data from the maximum activation trial. EMG data were then smoothed with a $500 \mathrm{~ms}$ moving average. Activation onsets were defined to occur when the smoothed EMG exceeded 2 SDs of the EMG baseline noise with the muscle at rest. Within each participant, we then defined an EMG transient for each muscle and each trial by averaging the rectified and filtered EMG data across repeated muscle activations within a time window spanning $1 \mathrm{~s}$ before to $3 \mathrm{~s}$ after the activation onset of the primary muscle for the trial. To define significant EMG magnitude changes, we performed group statistics on the maximum of the EMG transient for muscles of interest within each participant. To define significant temporal shifts between EMG signals, we quantified temporal shifts in each participant by determining the maximum cross-correlation between a pair of EMG transients (normalized to their maximum value).

fMRI acquisition and analysis. In 14 participants, we measured brain activation associated with the voluntary muscle activation tasks (described above) using fMRI. We used a 3 tesla (GE Signa Excite) with an eight-channel head coil. We positioned participants supine while viewing a fixation crosshair, and placed foam pads to limit head motion. As in previous fMRI studies of PFM activation (Schrum et al., 2011), we collected T2-weighted echo planar image volumes with blood oxygen leveldependent (BOLD) contrast (echo time, $34.5 \mathrm{~ms}$; flip angle, $90^{\circ}$; field of view, $220 \mathrm{~mm}$; pixel size, $3.43 \mathrm{~mm}$ ) continually every $2.5 \mathrm{~s}$ during three imaging runs. Each volume consisted of 37 axial slices $(3 \mathrm{~mm}$ slice thickness, $0.5 \mathrm{~mm}$ interslice gaps) that covered the brain from vertex to cerebellum. We additionally acquired a T1-weighted high-resolution anatomical image from each participant. We cued participants to voluntarily activate each muscle group (to $\sim 20 \%$ effort) in three separate runs-PFM activation run, GMM activation run, and FDI activation run-as described above, with the exception that participants performed additional activation blocks (6 blocks of 10 activations) in the scanner. All 14 participants performed PFM activation runs, 12 participants performed GMM activation runs, and 10 participants performed FDI activation runs.

We preprocessed each participant's fMRI data using the FMRIB (Functional Magnetic Resonance Imaging of the Brain) Expert Analysis Tool (FEAT, http://fsl.fmrib.ox.ac.uk/fsl/fslwiki/), which included skull extraction using the brain extraction tool (BET) in FSL (FMRIB Software Library), slice timing correction, motion correction, and spatial smoothing using a Gaussian kernel with full-width half-maximum of $5 \mathrm{~mm}$ and nonlinear high-pass temporal filtering (100 s). We used a general linear model (GLM) to examine the changes in BOLD signal associated with muscle activation for the three tasks. We performed participant-level whole-brain GLM analyses of individual runs in each participant to determine the change in BOLD signal during the activation blocks compared with the rest blocks. We then performed a group-level mixed-effect (FLAME 1 in FSL) analysis, with unpaired two-sided $t$ tests, to identify voxels in standard Montreal Neurological Institute (MNI) coordinates with significant differences in response based on the muscle group being voluntary contracted by the participant. We thresholded group-level images with cluster-based correction for multiple comparisons with $\mathrm{Z}>2.3$ and $p<0.05$. We made inferences about specific Brodmann areas (BA) using the Jülich Histological Atlas within FSL (Eickhoff et al., 2005).

TMS acquisition and analysis. In eight participants, we obtained motor-evoked potentials (MEP) from the PFM, with participants resting supine, using a single-pulse magnetic stimulator (Magstim 2002, The Magstim Company) with a $110 \mathrm{~mm}$ double cone coil. We sampled EMG signal at $16,000 \mathrm{~Hz}$, bandpass filtered at $1-1000 \mathrm{~Hz}$, and amplified at a gain of 9500. Our fMRI findings and previous studies have shown that pelvic floor musculature is represented in the medial wall (Leyton and Sherrington, 1917; Schrum et al., 2011). To localize the PFM representation in the anterior-posterior direction, we stimulated along the midline. We identified a participant-specific midline and central sulcus location 
A

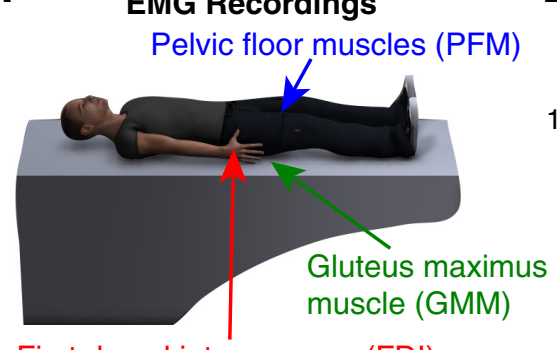

First dorsal interosseous (FDI)

C

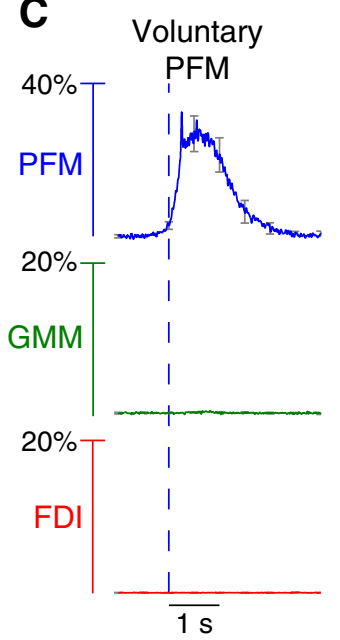

B

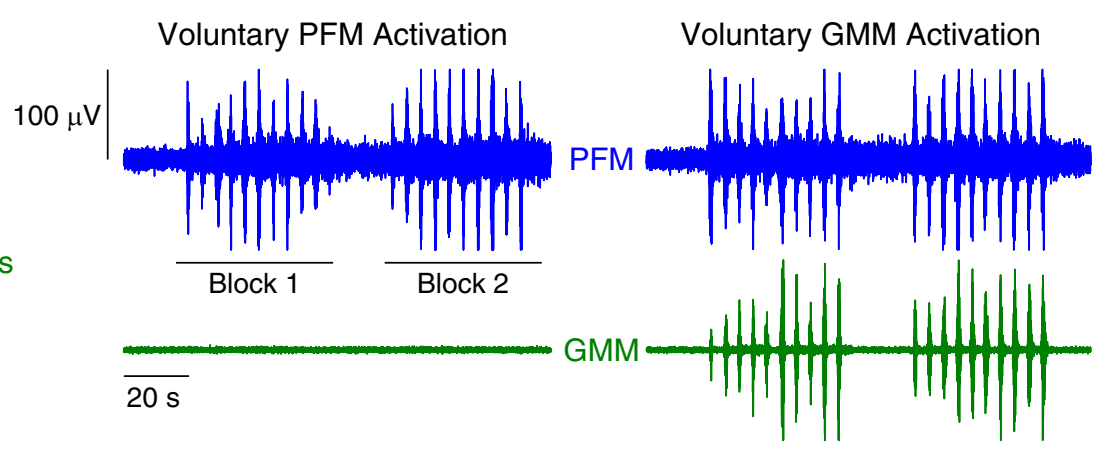

$\mathbf{E}$

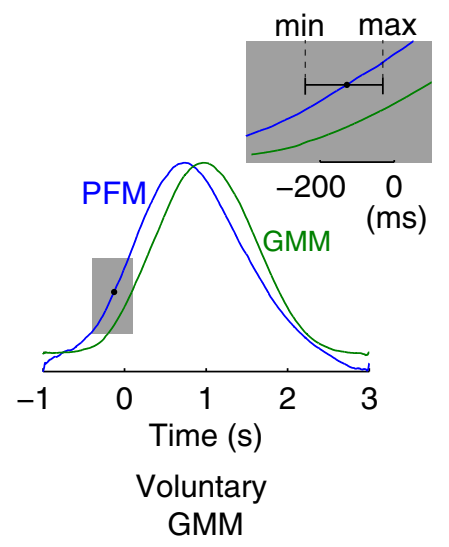

Figure 1. EMG evidence of pelvic floor muscle synergies. $A$, EMG signals from the PFM (blue), GMM (green), and the FDI (red) were recorded during separate trials that focused on the voluntary activation of each of these muscle groups. $\boldsymbol{B}$, Example EMG recordings from the PFM and GMM muscles in a single participant during repeated voluntary PFM activation and separate voluntary GMM activation. Participants performed two blocks of 10 activations, each activation lasting $2 \mathrm{~s}$. We observed PFM muscle activation during voluntary GMM muscle activation, but no GMM muscle activation during voluntary PFM muscle activation. C, Group data demonstrating the consistent finding of synergistic activation of the PFM muscles during voluntary GMM muscle activation but not during voluntary FDI muscle activation. Moreover, we did not find evidence of FDI or GMM muscle activation during voluntary PFM muscle activation. Curves show the average EMG transient triggered by the onset of the primary voluntary muscle of the task, averaged across participants (error bars indicate SEM across participants). D, Statistical analysis of group data shows that PFM activity is significantly greater ( ${ }^{*} p<0.01$ ) during voluntary GMM activation compared with PFM activity during voluntary FDI activation. The activity in the primary muscles of the tasks (GMM and FDI) was not significantly different ( $p=0.40$, n.s.; error bars indicate SEM across participants). $\boldsymbol{E}$, Analysis of the normalized EMG transients for the PFM and GMM muscles during voluntary GMM muscle activation revealed that activation of PFM muscles led GMM muscle activation by an average of $128 \mathrm{~ms}$ across participants (minimum of $30.5 \mathrm{~ms}$ and maximum of $239.5 \mathrm{~ms} ; p=0.001$ ).

by registering the participant's head with their T1-weighted 3D highresolution anatomical image using Brainsight Frameless (Rogue Research). We then used Brainsight to guide the TMS coil position to the midline and to record anterior-posterior position in MNI coordinates. We applied stimulations at seven to nine locations (based on the shape and size of participant's head), $1 \mathrm{~cm}$ apart, with the most posterior location at $2 \mathrm{~cm}$ posterior of the central sulcus. This led to the stimulation locations to lie between -60 and $20 \mathrm{~mm}$, along the anterior-posterior direction in MNI coordinates, across all the participants. To select an appropriate stimulus intensity for each participant, we inspected the average PFM EMG signal in response to seven pulses at each of several sites within $2 \mathrm{~cm}$ of central sulcus, and selected the stimulus intensity as the minimum intensity to evoke a clearly distinguishable MEP (Tsao et al., 2008). We used average response to obtain pelvic MEPs because the PFM are active even during rest, which makes it difficult to detect a small response to TMS (Mills and Nithi, 1997).

We calculated the MEP magnitude as the peak-to-peak magnitude of the average MEP in the time window of 10 to $100 \mathrm{~ms}$ after TMS pulse onset (Pelliccioni et al., 1997; Turnbull et al., 1999; Lefaucheur, 2005). To compare among participants, we normalized MEP magnitudes with respect to the maximum MEP magnitude within each participant. For statistical analysis, we divided the stimulation locations into three location bins (posterior, middle, and anterior) along the midline. We selected the bin edges to make the middle region correspond with the precentral gyrus as defined by the Harvard-Oxford Cortical Structural Atlas in FSL.
We defined the middle region by identifying the most posterior and most anterior coronal slice that contained no voxels with nonzero probability of belonging to the precentral gyrus. Therefore, we defined stimulation locations as those in the following ranges: posterior $y=-60$ to $-38 \mathrm{~mm}$, middle $y=-38$ to $-12 \mathrm{~mm}$, and anterior $y=-12$ to $20 \mathrm{~mm}$. We performed a one-way ANOVA of the MEP magnitude using the factor of location bin.

\section{Results}

Using recordings from the PFM, GMM, and FDI (Fig. 1A), we found that PFM activity is synergistically coupled with GMM activity, and that PFM synergistic coupling did not exist for distal extremity muscles such as the FDI. We found cross-correlation between PFM and GMM surface EMG electrodes was $3.20 \pm$ $0.57 \%$ across participants. Example recordings from a single participant shows that during repeated activation of the PFM, the GMM remained inactive (Fig. $1 B$ ). However, when the participant repeatedly activated the GMM, the PFM activated in a synchronous fashion (Fig. 1B). Group data of EMG transients time-locked to activation of the primary muscle demonstrated that we consistently observed this synergistic coupling of the PFM across the study population (Fig. 1C). PFM was activated during voluntary activation of the PFM and voluntary activation 
A

fMRI muscle activation tasks:
Pelvic floor muscles (PFM)
Gluteus maximus muscle (GMM)
First dorsal interosseous (FDI)

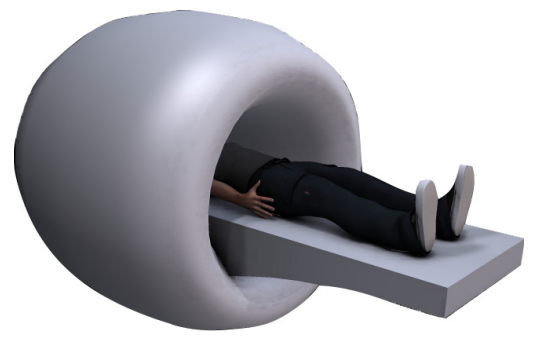

B

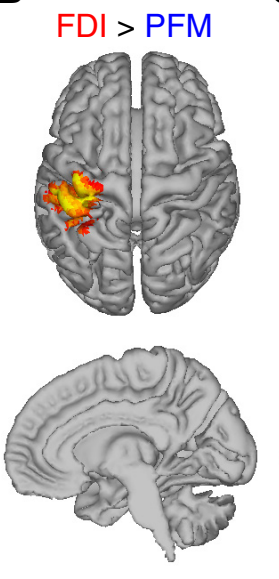

Z 2.3
C

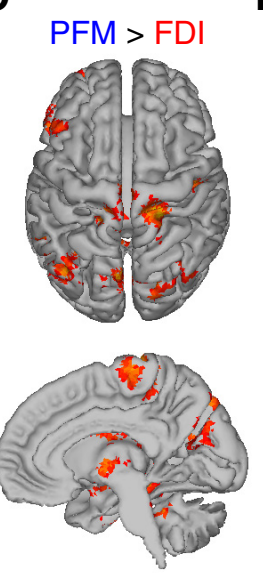

D

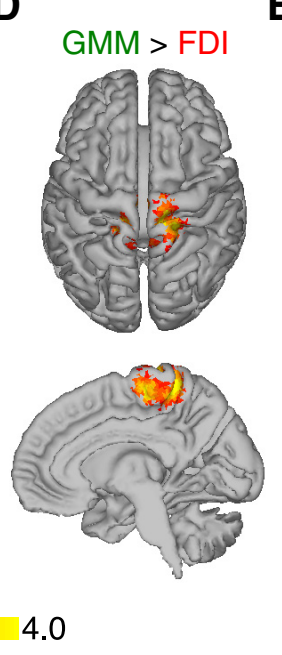

E

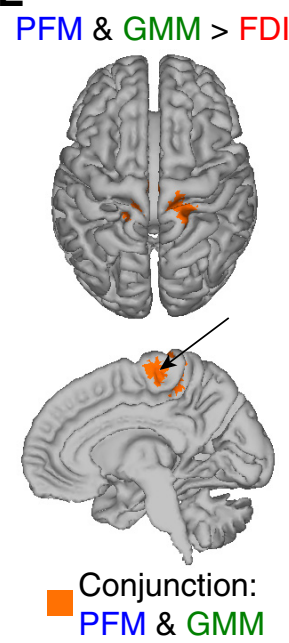

Figure 2. fMRI evidence of overlapping activity during voluntary PFM and voluntary GMM activation. $A$, fMRI data were collected while participants performed three separate runs identical to the EMG tasks: separate repeated voluntary activation of PFM (run 1), GMM (run 2), and FDI (run 3). B. Contrast of voluntary FDI activation greater than voluntary PFM activation produced significant brain activation in left sensorimotor cortex. C, Contrast of voluntary PFM activation greater than voluntary FDI activation produced significant activation in the medial wall of the precentral gyrus. $\boldsymbol{D}$, Contrast of voluntary GMM activation greater than voluntary FDI activation produced significant activation in the medial wall of the precentral gyrus $\boldsymbol{E}$, Anterior medial wall of the precentral gyrus exhibited significant brain activation for both PFM activation and GMM activation compared with FDI activation.

A
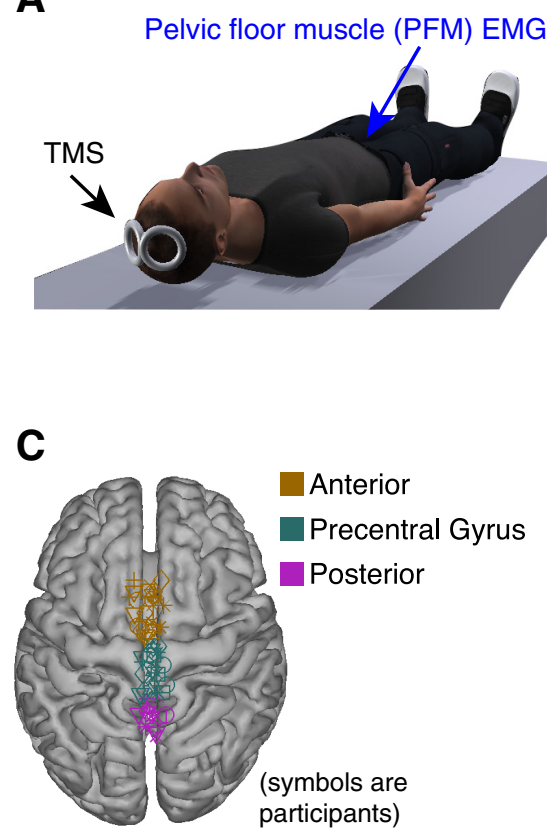

B

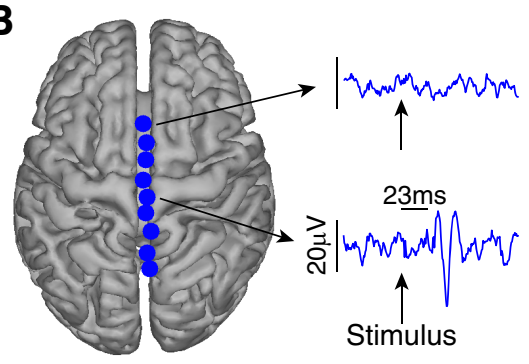

D

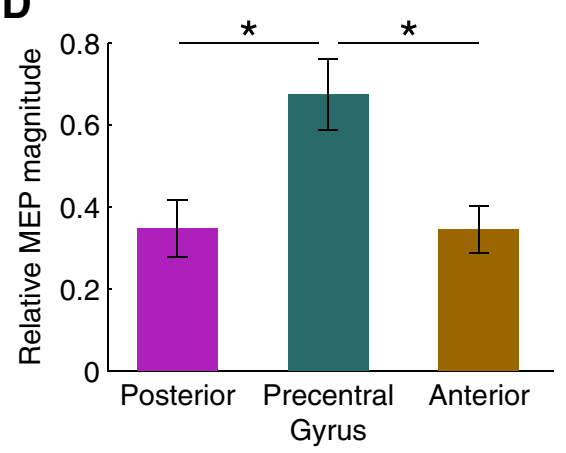

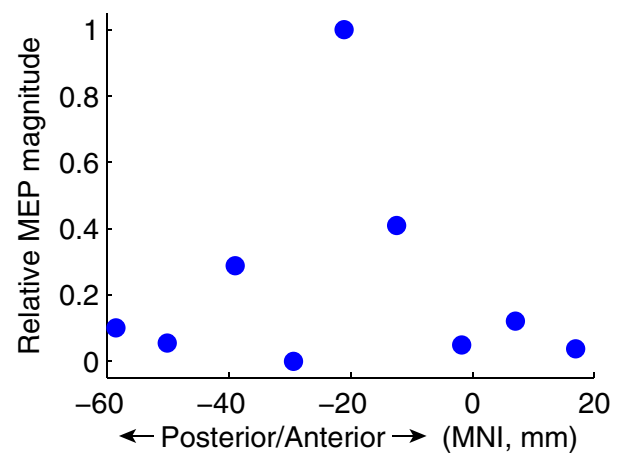

$\mathbf{E}$

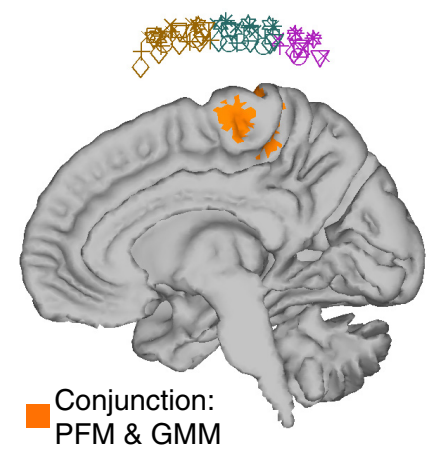

Figure 3. TMS evidence that region of brain activation overlap between voluntary PFM activation and voluntary GMM activation is associated with the activity in PFM muscles. $A$, We collected MEP from the PFM muscles generated by TMS along the midline of the participant's brain. $\boldsymbol{B}$, Single participant data showing an MEP in the PFM muscles generated by stimulating over precentral gyrus at a latency of $23 \mathrm{~ms}$. Stimulating at points not over the precentral gyrus did not generate significant MEPs. The MEP in the PFM peaked at an MNI coordinate at approximately - $20 \mathrm{~mm}$. C, Locations of applied stimulation across all participants confined over the midline and divided (binned) into posterior, middle (precentral gyrus), and anterior bins. D, ANOVA analysis revealed that bin location had a significant main effect on MEP magnitude $\left({ }^{*} p=0.003\right)$. MEPs corresponding to the middle bin were significantly greater than either the posterior bin $(p=0.001)$ or anterior bin $(p=0.016)$. Error bars indicate SEM across participants. $E$, Stimulation points classified as precentral gyrus were above the fMRI-identified region of activation common to both voluntary PFM activation and voluntary GMM activation.

of the GMM, but not during voluntary activation of the FDI. A correlation analysis of PFM activity as a function of GMM activity during GMM tasks revealed a slight positive correlation, which did not reach statistical significance across the participants we studied (slope $=0.2694$ with $95 \%$ confidence interval of
-0.00091 to 0.5398$)$. All participants voluntarily activated their muscles, as instructed, to moderate levels. On average, participants activated PFM to $34 \%$ of MVC, the GMM to $13 \%$ of MVC, and the FDI to $15 \%$ of MVC. Importantly, while GMM and FDI activation did not significantly differ across participants (paired $t$ 


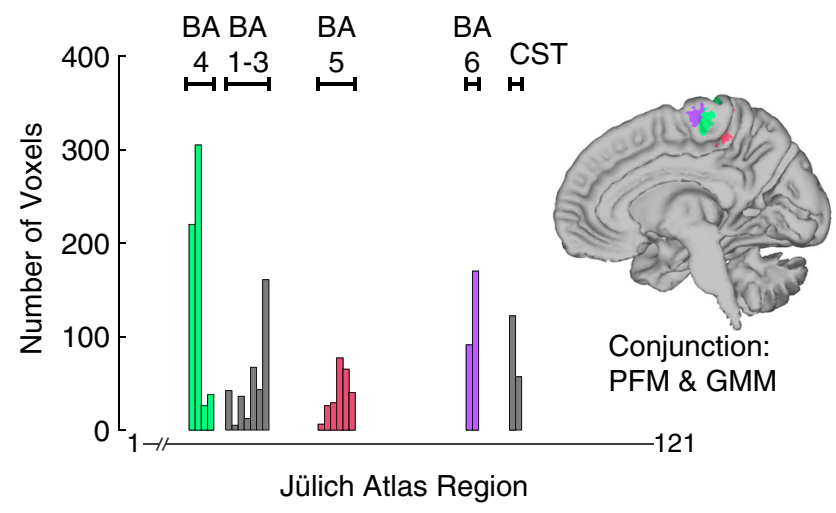

Figure 4. Evidence of motor cortical representation in the overlapping brain activation during voluntary PFM and voluntary GMM activation. We computed the number of voxels in the overlap that were most likely to belong to each of the 121 regions in the Jülich Histological Atlas within FSL. The range of atlas regions included in each BA are labeled. CST, Corticospinal tract.

Table 1. Peak foci for activation in the region of overlap obtained during voluntary PFM and voluntary GMM activation

\begin{tabular}{|c|c|c|c|c|}
\hline \multirow[b]{2}{*}{ Region } & \multicolumn{2}{|l|}{$\mathrm{PFM}>\mathrm{FDI}$} & \multicolumn{2}{|l|}{$\mathrm{GMM}>\mathrm{FDI}$} \\
\hline & $\begin{array}{l}\text { Coordinates } \\
x, y, z(\mathrm{~mm})\end{array}$ & Zscore & $\begin{array}{l}\text { Coordinates } \\
x, y, z(\mathrm{~mm})\end{array}$ & Zscore \\
\hline Primary motor cortex (4) & $20,-32,64$ & 4.70 & $18,-30,68$ & 4.86 \\
\hline Premotor cortex (SMA, 6) & $-4,-20,66$ & 3.16 & $-4,-22,64$ & 3.82 \\
\hline Primary somatosensory cortex (1-3) & $-16,-34,66$ & 3.74 & $16,-36,64$ & 4.67 \\
\hline Superior parietal lobule (5) & $-6,-40,48$ & 2.98 & $10,-40,54$ & 4.07 \\
\hline
\end{tabular}

Significance: $Z>2.3, p<0.05$, cluster-corrected for multiple comparisons. Coordinates in standard MNI space.

test, $p=0.40$ ), PFM activation reached an average of $26 \%$ of MVC during voluntary GMM activation, which was significantly greater than PFM activation during voluntary FDI activation (paired $t$ test, $p=0.005$ ) (Fig. $1 D$ ). We observed that PFM activation occurred in advance of GMM activation during voluntary GMM activation (Fig. 1E). Cross-correlating the average EMG transient from the PFM and from the GMM during voluntary GMM activation, we found that activation in PFM led GMM activation by an average of $128 \mathrm{~ms}$, which was significantly greater than 0 (maximum of $239.5 \mathrm{~ms}$ and minimum of $30.5 \mathrm{~ms}$, $t$ test, $p=0.001)$.

Using fMRI data collected while participants performed muscle activation tasks identical to those described above (Fig. 2A), we found that a region of the medial wall of the precentral gyrus was activated during voluntary PFM activation and voluntary GMM activation, but not during voluntary FDI activation. We used FDI activation as a reference task in fMRI analysis because the EMG results showed that there was neither PFM nor GMM muscle activation during voluntary FDI activation. As expected, the contrast of FDI activation greater than PFM activation produced significant brain activity primarily in left sensorimotor cortex (Fig. 2B), as the participant activated the right FDI. Also, as expected, the contrast of PFM activation greater than FDI activation produced significant activity in the medial wall of the precentral gyrus (Fig. 2C). Surprisingly, the contrast of GMM activation greater than FDI activation, which EMG data suggest contains increased GMM activation and increased PFM activation, also produced significant activation in the medial wall of the precentral gyrus (Fig. 2D). We found a region of the medial wall of the precentral gyrus that exhibited significant brain activation for both voluntary PFM activation and voluntary GMM activation compared with FDI activation (Fig. 2E).
Using MEP data generated by application of TMS along the midline of the participant's brain (Fig. $3 A$ ), we verified that medial wall of the precentral gyrus, identified using fMRI to be active during both PFM activation and GMM activation, is likely associated with PFM activation. Example data from one participant illustrates the findings (Fig. $3 B$ ). Stimulation over anterior points of the midline over frontal cortex did not produce an MEP in the PFM, but stimulation over the precentral gyrus at the same stimulus intensity produced an MEP in the PFM at a latency of $23 \mathrm{~ms}$. In this participant, the relative magnitude of the MEP in the PFM peaked at an MNI coordinate at approximately $-20 \mathrm{~mm}$. The locations where we applied stimulation across all participants were confined over the midline, and were divided into posterior, middle (precentral gyrus), and anterior bins (Fig. 3C). We observed that there was a significant main effect of bin location on PFM MEP magnitude, $F_{(2,21)}=7.95, p=0.003$. A post hoc multiple-comparisons test with Bonferroni correction $(p<0.05)$ indicated that MEPs corresponding to the middle bin were significantly greater than either the posterior bin $(p=0.001)$ or anterior bin $(p=0.016)$ (Fig. $3 D)$. Viewing the stimulation points and the medial wall together demonstrated that stimulation points that we classified as precentral gyrus were above the fMRI-identified region of brain activation overlap for both voluntary PFM activation and voluntary GMM activation (Fig. 3E).

We found that the brain region with overlapping activation during both voluntary PFM and voluntary GMM activation (Fig. $3 E$ ) contained contributions from both primary motor cortex (BA 4) and supplementary motor area (SMA; BA 6) (Fig. 4), adding additional support to the likely motor involvement of this overlap region. We found that $36.0 \%$ of overlapping voxels were most likely BA 4, 22.3\% were most likely primary somatosensory cortex (BA 1-3), 15.9\% were most likely BA 6, 14.8\% were superior parietal lobule (BA 5), and $10.9 \%$ were most likely corticospinal tract. The foci of peak activation in the overlap region for PFM activation and GMM activation were $4.9 \mathrm{~mm}$ apart in primary motor cortex and 2.9 mm apart in SMA (Table 1).

\section{Discussion}

Our results indicate that motor areas of the cerebral cortex may be associated with the synergistic activation of the pelvic floor that has been shown to accompany voluntary activation of hip and trunk muscles (Bø and Stien, 1994; Hodges et al., 2007). The cortical area associated with this pelvic floor activation is the medial wall of the precentral gyrus, consistent with previous motor cortex stimulation studies in both animals and humans (Leyton and Sherrington, 1917; Turnbull et al., 1999). More specifically, this identified region in the medial wall appears to contain a clear contribution from both BA 6 (SMA) and BA 4 [primary motor cortex (M1)].

Numerous previous studies have demonstrated the importance of SMA during voluntary activation of the pelvic floor (Blok et al., 1997; Zhang et al., 2005; Seseke et al., 2006; Schrum et al., 2011). The SMA is generally thought to be involved in higherorder organization and preparation of voluntary movement (Cunnington et al., 1996). SMA has functionally and neuroanatomically distinct regions; for example, an anterior portion known as the pre-SMA and a posterior portion known as the SMA proper (Luppino et al., 1993; Rizzolatti et al., 1996). The SMA proper contains direct corticospinal neurons (Dum and Strick, 1996) and has been shown to be involved in movement execution similar to the primary motor cortex (Macpherson et al., 1982; Picard and Strick, 1996; Boecker et al., 1998; Lee et al., 
1999). Pre-SMA is thought to be more involved with motor planning associated with self-initiated tasks, and may be active even during motor imagery in the absence of movement execution (Tyszka et al., 1994; Stephan et al., 1995; Deiber et al., 1999; Cunnington et al., 2002). Our cortical mapping results of the PFM appear to coincide with SMA proper.

To our knowledge, there has been relatively little discussion regarding the functional interpretation of why the pelvic floor would have a relatively strong representation in SMA. As in previous studies of pelvic floor muscle synergies, our findings support that PFM activation occurs before the primary muscle of the task. Data from a variety of approaches, including electroencephalography and fMRI, suggest that SMA activity precedes primary motor cortical activity during voluntary motor tasks (Ball et al., 1999; Soon et al., 2008; Bortoletto and Cunnington, 2010). We suggest that the SMA representation of the pelvic floor is part of the neural substrate associated with the feedforward pelvic floor activation in advance of hip and trunk muscles, as we and others have shown (Hodges et al., 2007; Sjödahl et al., 2009). If this suggestion is correct, circuits within SMA may be involved in evaluating the demands of the voluntary motor task at hand and activating the pelvic floor in preparation if necessary (as in the case of gluteal activation) or unnecessary (as in the case of voluntary finger muscle activation).

Our results are therefore consistent with suspected involvement of SMA in feedforward muscle synergies underlying postural control. Patients with SMA lesions exhibit impairments in anticipatory muscle activation (Viallet et al., 1992). Neuroimaging in healthy controls suggest there is SMA activation associated with performing anticipatory postural adjustments (APA) (Ng et al., 2012). Additionally, repetitive TMS of SMA has been shown to affect the timing of APA in both healthy controls and patients with Parkinson's disease (Jacobs et al., 2009). It has been previously suggested that PFM synergies may be part of an APA when perturbations to abdominal pressure are predictable (Hodges et al., 2007); our work critically defines a neural substrate that may underlie these adjustments in pelvic floor muscle activation.

One limitation of our study is that the PFM are not a single muscle group, but are in fact a complex set of multiple muscles with different mechanical actions that may function together or independently, based on the task (Bharucha, 2006; Stafford et al., 2012). Whereas our results demonstrate cortical activation that is associated with muscle activity as recorded at the anal sphincter, future studies will be required to define exactly which combination of PFM operate synergistically for different tasks. It is possible that PFM operate with each other in the same combination during synergies with non-PFM as they do during voluntary PFM contraction, or conversely, PFM synergies may only recruit specific subsets of the PFM to maintain continence with minimal muscle effort. We also limited our study to a low narrow range of GMM activation intensities, which necessitates future studies to define the scaling properties of muscle synergies between the PFM and GMM. Previous studies investigating PFM synergies with the abdominal muscles have shown an increase in PFM activity with an increase in abdominal muscle activity (Sjödahl et al., 2009; Junginger et al., 2010).

Here we have shown that a motor cortical region that generates PFM contraction is active during synergistic activation of the pelvic floor. Our current study conclusions are limited in scope because we have not yet established that PFM synergies are cortically structured. Previous work has hypothesized that certain muscle synergies could be structured at a cortical level (Rathelot and Strick, 2006). Cortical structuring of PFM synergies would imply that activation of the medial wall motor cortical area identified in this study causes the PFM synergy. At present, we do not know the extent of subcortical involvement in the PFM synergy. For example, it is known that there are centers in the pons that facilitate PFM activity in subconscious control of urination (Fowler et al., 2008), but we do not currently know their contribution to the identified PFM synergies. It is possible that the cortical representation of the GMM (or other muscle group synergistic with the PFM) sends projections to subcortical centers that structure the PFM synergy, and that the medial wall region we identified contributes to, but does not cause, the PFM synergy. The medial wall region associated with PFM activation identified in our study is part of more rostral M1 and thus less likely to have direct connections to spinal motoneuronal pools compared with more caudal M1 (Rathelot and Strick, 2009). We therefore hypothesize that synergistic coupling among individual pelvic floor muscles is structured at the subcortical level, but the synergistic coupling between the pelvic floor and other muscle groups (e.g., GMM) may be structured by cortical connections. Future experiments, including repetitive TMS downregulation (Jacobs et al., 2009) of medial wall regions that activate the PFM, as well as expanded TMS mapping of PFM activation at cortical locations that activate synergistic muscles (e.g., gluteal, abdominal, shoulder), will be necessary to determine whether the medial wall motor cortical activation identified in the current work indeed reflects cortical structuring of the PFM synergy.

Finally, our results have important clinical implications for understanding motor cortical mechanisms of chronic pelvic pain. It was recently shown that women with the prevalent condition of interstitial cystitis/painful bladder syndrome (IC/PBS) have significant changes in resting state neural activity, compared with healthy controls, in areas of the medial wall of SMA (Kilpatrick et al., 2014). The precise function of this region was not investigated in these patients, but the authors interpreted the results in the context of possible motor control mechanisms contributing to the condition (Butrick, 2009a,b). The results of our present study are from a male population, but major sex differences in the cortical control of the pelvic floor are not immediately suspected (Seseke et al., 2006). The motor cortical region we have identified to be associated with PFM activation clearly overlaps with the coordinates reported for patientspecific alterations in IC/PBS. Therefore, our results may suggest that changes in motor cortical areas that influence pelvic floor motor neuron pools may play a critical role in IC/PBS pathophysiology.

\section{References}

Aagaard P, Simonsen EB, Andersen JL, Magnusson SP, Bojsen-Møller F, Dyhre-Poulsen P (2000) Antagonist muscle coactivation during isokinetic knee extension. Scand J Med Sci Sports 10:58-67. CrossRef Medline

Aruin AS (2002) The organization of anticipatory postural adjustments. J Automatic Control 12:31-37. CrossRef

Ashton-Miller JA, DeLancey JO (2007) Functional anatomy of the female pelvic floor. Ann N Y Acad Sci 1101:266-296. CrossRef Medline

Ball T, Schreiber A, Feige B, Wagner M, Lücking CH, Kristeva-Feige R (1999) The role of higher-order motor areas in voluntary movement as revealed by high-resolution EEG and fMRI. Neuroimage 10:682-694. CrossRef Medline

Bharucha A (2006) Pelvic floor: anatomy and function. Neurogastroenterol Motility 18:507-519. CrossRef

Blok BF, Sturms LM, Holstege G (1997) A PET study on cortical and sub- 
cortical control of pelvic floor musculature in women. J Comp Neurol 389:535-544. CrossRef Medline

Bø K, Stien R (1994) Needle EMG registration of striated urethral wall and pelvic floor muscle activity patterns during cough, Valsalva, abdominal, hip adductor, and gluteal muscle contractions in nulliparous healthy females. Neurourol Urodyn 13:35-41. CrossRef Medline

Boecker H, Dagher A, Ceballos-Baumann AO, Passingham RE, Samuel M, Friston KJ, Poline J, Dettmers C, Conrad B, Brooks DJ (1998) Role of the human rostral supplementary motor area and the basal ganglia in motor sequence control: investigations with H2 $15 \mathrm{O}$ PET. J Neurophysiol 79: 1070-1080. Medline

Bortoletto M, Cunnington R (2010) Motor timing and motor sequencing contribute differently to the preparation for voluntary movement. Neuroimage 49:3338-3348. CrossRef Medline

Butrick CW (2009a) Pathophysiology of pelvic floor hypertonic disorders. Obstet Gynecol Clin North Am 36:699-705. CrossRef Medline

Butrick CW (2009b) Pelvic floor hypertonic disorders: identification and management. Obstet Gynecol Clin North Am 36:707-722. CrossRef Medline

Cheung VC, Piron L, Agostini M, Silvoni S, Turolla A, Bizzi E (2009) Stability of muscle synergies for voluntary actions after cortical stroke in humans. Proc Natl Acad Sci U S A 106:19563-19568. CrossRef Medline

Cunnington R, Bradshaw JL, Iansek R (1996) The role of the supplementary motor area in the control of voluntary movement. Hum Movement Sci 15:627-647. CrossRef

Cunnington R, Windischberger C, Deecke L, Moser E (2002) The preparation and execution of self-initiated and externally-triggered movement: a study of event-related fMRI. Neuroimage 15:373-385. CrossRef Medline

Deiber MP, Honda M, Ibañez V, Sadato N, Hallett M (1999) Mesial motor areas in self-initiated versus externally triggered movements examined with fMRI: effect of movement type and rate. J Neurophysiol 81:30653077. Medline

Doggweiler-Wiygul R (2004) Urologic myofascial pain syndromes. Curr Pain Headache Rep 8:445-451. CrossRef Medline

Doggweiler-Wiygul R, Wiygul JP (2002) Interstitial cystitis, pelvic pain, and the relationship to myofascial pain and dysfunction: a report on four patients. World J Urol 20:310-314. Medline

Drew T, Andujar JE, Lajoie K, Yakovenko S (2008) Cortical mechanisms involved in visuomotor coordination during precision walking. Brain Res Rev 57:199-211. CrossRef Medline

Dum RP, Strick PL (1996) Spinal cord terminations of the medial wall motor areas in macaque monkeys. J Neurosci 16:6513-6525. Medline

Eickhoff SB, Stephan KE, Mohlberg H, Grefkes C, Fink GR, Amunts K, Zilles K (2005) A new SPM toolbox for combining probabilistic cytoarchitectonic maps and functional imaging data. Neuroimage 25:1325-1335. CrossRef Medline

Floyd WF, Walls EW (1953) Electromyography of the sphincter ani externus in man. J Physiol 122:599-609. Medline

Fowler CJ, Griffiths D, de Groat WC (2008) The neural control of micturition. Nat Rev Neurosci 9:453-466. CrossRef Medline

Hodges PW, Sapsford R, Pengel LH (2007) Postural and respiratory functions of the pelvic floor muscles. Neurourol Urodyn 26:362-371. CrossRef Medline

Jacobs JV, Lou JS, Kraakevik JA, Horak FB (2009) The supplementary motor area contributes to the timing of the anticipatory postural adjustment during step initiation in participants with and without Parkinson's disease. Neuroscience 164:877-885. CrossRef Medline

Junginger B, Baessler K, Sapsford R, Hodges PW (2010) Effect of abdominal and pelvic floor tasks on muscle activity, abdominal pressure and bladder neck. Int Urogynecol J 21:69-77. CrossRef Medline

Kilpatrick LA, Kutch JJ, Tillisch K, Naliboff BD, Labus JS, Jiang Z, Farmer MA, Apkarian AV, Mackey S, Martucci KT, Clauw DJ, Harris RE, Deutsch G, Ness TJ, Yang CC, Maravilla K, Mullins C, Mayer EA (2014) Alterations in resting state oscillations and connectivity within sensory and motor networks in women with interstitial cystitis/painful bladder syndrome. J Urol 192:947-955. CrossRef Medline

Kuhtz-Buschbeck JP, van der Horst C, Wolff S, Filippow N, Nabavi A, Jansen O, Braun PM (2007) Activation of the supplementary motor area (SMA) during voluntary pelvic floor muscle contractions: an fMRI study. Neuroimage 35:449-457. CrossRef Medline
Lee KM, Chang KH, Roh JK (1999) Subregions within the supplementary motor area activated at different stages of movement preparation and execution. Neuroimage 9:117-123. CrossRef Medline

Lefaucheur JP (2005) Excitability of the motor cortical representation of the external anal sphincter. Exp Brain Res 160:268-272. CrossRef Medline

Leyton A, Sherrington CS (1917) Observations on the excitable cortex of the chimpanzee, orangutan, and gorilla. Exp Physiol 11:135-222.

Luppino G, Matelli M, Camarda R, Rizzolatti G (1993) Corticocortical connections of area F3 (SMA-proper) and area F6 (pre-SMA) in the macaque monkey. J Comp Neurol 338:114-140. CrossRef Medline

Macpherson J, Wiesendanger M, Marangoz C, Miles TS (1982) Corticospinal neurones of the supplementary motor area of monkeys. Exp Brain Res 48:81-88. Medline

Madill SJ, McLean L (2008) Quantification of abdominal and pelvic floor muscle synergies in response to voluntary pelvic floor muscle contractions. J Electromyogr Kinesiol 18:955-964. CrossRef Medline

Mills KR, Nithi KA (1997) Corticomotor threshold to magnetic stimulation: normal values and repeatability. Muscle Nerve 20:570-576. CrossRef Medline

Mussa-Ivaldi FA, Giszter SF, Bizzi E (1994) Linear combinations of primitives in vertebrate motor control. Proc Natl Acad Sci U S A 91:7534-7538. CrossRef Medline

Ng TH, Sowman PF, Brock J, Johnson BW (2012) Neuromagnetic brain activity associated with anticipatory postural adjustments for bimanual load lifting. Neuroimage 66C:343-352. CrossRef Medline

Parekh AR, Feng MI, Kirages D, Bremner H, Kaswick J, Aboseif S (2003) The role of pelvic floor exercises on post-prostatectomy incontinence. J Urol 170:130-133. CrossRef Medline

Pelliccioni G, Scarpino O, Piloni V (1997) Motor evoked potentials recorded from external anal sphincter by cortical and lumbo-sacral magnetic stimulation: normative data. J Neurol Sci 149:69-72. CrossRef Medline

Peschers UM, Gingelmaier A, Jundt K, Leib B, Dimpfl T (2001) Evaluation of pelvic floor muscle strength using four different techniques. Int Urogynecol J Pelvic Floor Dysfunct 12:27-30. CrossRef Medline

Picard N, Strick PL (1996) Motor areas of the medial wall: a review of their location and functional activation. Cereb Cortex 6:342-353. CrossRef Medline

Rathelot JA, Strick PL (2006) Muscle representation in the macaque motor cortex: an anatomical perspective. Proc Natl Acad Sci U S A 103:82578262. CrossRef Medline

Rathelot JA, Strick PL (2009) Subdivisions of primary motor cortex based on cortico-motoneuronal cells. Proc Natl Acad Sci U S A 106:918-923. CrossRef Medline

Rizzolatti G, Luppino G, Matelli M (1996) The classic supplementary motor area is formed by two independent areas. Adv Neurol 70:45-56. Medline

Saltiel P, Wyler-Duda K, D’Avella A, Tresch MC, Bizzi E (2001) Muscle synergies encoded within the spinal cord: evidence from focal intraspinal NMDA iontophoresis in the frog. J Neurophysiol 85:605-619. Medline

Sapsford RR, Hodges PW (2001) Contraction of the pelvic floor muscles during abdominal maneuvers. Arch Phys Med Rehabil 82:1081-1088. CrossRef Medline

Schrum A, Wolff S, van der Horst C, Kuhtz-Buschbeck JP (2011) Motor cortical representation of the pelvic floor muscles. J Urol 186:185-190. CrossRef Medline

Seseke S, Baudewig J, Kallenberg K, Ringert RH, Seseke F, Dechent P (2006) Voluntary pelvic floor muscle control: an fMRI study. Neuroimage 31: 1399-1407. CrossRef Medline

Sjödahl J, Kvist J, Gutke A, Öberg B (2009) The postural response of the pelvic floor muscles during limb movements: a methodological electromyography study in parous women without lumbopelvic pain. Clin Biomech 24:183-189. CrossRef Medline

Soon CS, Brass M, Heinze HJ, Haynes JD (2008) Unconscious determinants of free decisions in the human brain. Nat Neurosci 11:543-545. CrossRef Medline

Stafford RE, Ashton-Miller JA, Sapsford R, Hodges PW (2012) Activation of the striated urethral sphincter to maintain continence during dynamic tasks in healthy men. Neurourol Urodyn 31:36-43. CrossRef Medline 
Stephan KM, Fink GR, Passingham RE, Silbersweig D, Ceballos-Baumann AO, Frith CD, Frackowiak RS (1995) Functional anatomy of the mental representation of upper extremity movements in healthy subjects. J Neurophysiol 73:373-386. Medline

Tsao H, Galea MP, Hodges PW (2008) Reorganization of the motor cortex is associated with postural control deficits in recurrent low back pain. Brain 131:2161-2171. CrossRef Medline

Turnbull GK, Hamdy S, Aziz Q, Singh KD, Thompson DG (1999) The cortical topography of human anorectal musculature. Gastroenterology 117 : 32-39. CrossRef Medline

Tyszka JM, Grafton ST, Chew W, Woods RP, Colletti PM (1994) Parceling of mesial frontal motor areas during ideation and movement using functional magnetic resonance imaging at 1.5 tesla. Ann Neurol 35:746-749. CrossRef Medline
Viallet F, Massion J, Massarino R, Khalil R (1992) Coordination between posture and movement in a bimanual load lifting task: putative role of a medial frontal region including the supplementary motor area. Exp Brain Res 88:674-684. Medline

Waters-Metenier S, Husain M, Wiestler T, Diedrichsen J (2014) Bihemispheric transcranial direct current stimulation enhances effectorindependent representations of motor synergy and sequence learning. J Neurosci 34:1037-1050. CrossRef Medline

Winter DA, Fuglevand AJ, Archer SE (1994) Crosstalk in surface electromyography: theoretical and practical estimates. J Electromyogr Kinesiol 4:15-26. CrossRef Medline

Zhang H, ReitzA, Kollias S, Summers P, Curt A, Schurch B (2005) An fMRI study of the role of suprapontine brain structures in the voluntary voiding control induced by pelvic floor contraction. Neuroimage 24:174-180. CrossRef Medline 